\title{
A solid support generator of the Auger electron emitter rhodium-103m from [103Pd]palladium
}

Jensen, Andreas I.; Zhuravlev, Fedor; Severin, Gregory; Magnus, Charlotte Busk; Fonslet, Jesper; Köster, Ulli; Jensen, Mikael

Published in:

Applied Radiation and Isotopes

Link to article, DOI:

10.1016/j.apradiso.2019.108985

Publication date:

2020

Document Version

Peer reviewed version

Link back to DTU Orbit

Citation (APA):

Jensen, A. I., Zhuravlev, F., Severin, G., Magnus, C. B., Fonslet, J., Kä̈ster, U., \& Jensen, M. (2020). A solid support generator of the Auger electron emitter rhodium-103m from [ ${ }^{103}$ Pd]palladium. Applied Radiation and Isotopes, 156, [108985]. https://doi.org/10.1016/j.apradiso.2019.108985

\section{General rights}

Copyright and moral rights for the publications made accessible in the public portal are retained by the authors and/or other copyright owners and it is a condition of accessing publications that users recognise and abide by the legal requirements associated with these rights.

- Users may download and print one copy of any publication from the public portal for the purpose of private study or research.

- You may not further distribute the material or use it for any profit-making activity or commercial gain

- You may freely distribute the URL identifying the publication in the public portal 


\section{Journal Pre-proof}

A solid support generator of the Auger electron emitter rhodium-103m from $\left[{ }^{103}\right.$ Pd]palladium

Andreas I. Jensen, Fedor Zhuravlev, Gregory Severin, Charlotte Busk Magnus, Jesper Fonslet, Ulli Köster, Mikael Jensen

PII: S0969-8043(19)30656-6

DOI: https://doi.org/10.1016/j.apradiso.2019.108985

Reference: $\quad$ ARI 108985

To appear in: $\quad$ Applied Radiation and Isotopes

Received Date: 4 June 2019

Revised Date: 11 November 2019

Accepted Date: 11 November 2019

Please cite this article as: Jensen, A.I., Zhuravlev, F., Severin, G., Magnus, C.B., Fonslet, J., Köster, U., Jensen, M., A solid support generator of the Auger electron emitter rhodium-103m from [ ${ }^{103}$ Pd]palladium, Applied Radiation and Isotopes (2019), doi: https://doi.org/10.1016/ j.apradiso.2019.108985.

This is a PDF file of an article that has undergone enhancements after acceptance, such as the addition of a cover page and metadata, and formatting for readability, but it is not yet the definitive version of record. This version will undergo additional copyediting, typesetting and review before it is published in its final form, but we are providing this version to give early visibility of the article. Please note that, during the production process, errors may be discovered which could affect the content, and all legal disclaimers that apply to the journal pertain.

() 2019 Published by Elsevier Ltd. 


\title{
1 A solid support generator of the Auger electron emitter rhodium-103m 2 from [ $\left.{ }^{103} \mathrm{Pd}\right]$ palladium
}

Andreas I. Jensen ${ }^{a}$, Fedor Zhuravlev ${ }^{a}$, Gregory Severin ${ }^{\mathrm{a}, \mathrm{b}}$, Charlotte Busk Magnus ${ }^{\mathrm{a}}$, Jesper Fonslet ${ }^{\mathrm{a}}$, Ulli

a. Center for Nuclear Technologies (DTU Nutech), Technical University of Denmark (DTU), Frederiksborgvej 399, 4000 Roskilde, Denmark (contact: atije@dtu.dk).

b. Department of Chemistry and Facility for Rare Isotope Beams, Michigan State University, 578 S. Shaw Ln., East Lansing, MI, 48824, USA (contact: gwseverin@chemistry.msu.edu).

c. Institut Laue-Langevin, 71 avenue des Martyrs, 38042 Grenoble, France (contact: koester@ill.fr)

*Corresponding author: Andreas I. Jensen, e-mail: atije@dtu.dk

\begin{abstract}
Auger electron therapy is an attractive modality for targeting microscopic tumors. Rhodium-103m $\left({ }^{103 \mathrm{~m}} \mathrm{Rh}, \mathrm{T} 1 / 2=56.1 \mathrm{~min}\right)$ is a promising Auger electron emitter that can be obtained as the decay product of palladium-103 $\left({ }^{103} \mathrm{Pd}, \mathrm{T} 1 / 2=16.99\right.$ days). ${ }^{103} \mathrm{Pd}$ was chelated in a lipophilic derivative of the 16aneS4 macrocycle and trapped the complex on a C18 cartridge. Elution with dilute hydrochloric acid gave radiochemically pure ${ }^{103 \mathrm{~m}} \mathrm{Rh}$. We hypothesize this to be through a combination of the Szilard-Chalmers effect and transient ionization.
\end{abstract}

KEYWORDS: Auger radiotherapy, radionuclide generator, rhodium-103m, palladium-103, 16aneS4

\section{INTRODUCTION}


Metastasis is one of the major reasons for recurrence and consequent mortality in cancer (Steeg, 2016). Metastases may contain very few cells and be disseminated throughout the organism. This makes early stage diagnosis difficult and treatment by surgery or external radiotherapy impossible. Systemic chemotherapy may be used, but at the risk of powerful side effects that can be detrimental to continued treatment. Accordingly, there is an unmet need for treatments that can specifically target and cure micrometastatic disease (Grudzinski et al., 2018).

Targeted internal radiotherapy holds the promise of treating such disseminated cancers by employing radiolabeled compounds that specifically target tumor cells. While beta and alpha emissions are current choices for such therapy, the unique properties of Auger/Coster-Kronig electrons makes them an attractive choice for pin-point accuracy in internal radiotherapy. Auger electrons have, due to their very short range and high multiplicity, high linear energy transfer (LET)-like qualities. This makes them capable of inducing double-stranded DNA breaks (Reissig et al., 2016). Further, the short ranges of Auger electrons of less than a cell diameter makes it theoretically possible to effectively irradiate targeted cells, while largely sparing surrounding healthy tissue. For these reasons, Auger radiotherapy is considered a promising emerging field in nuclear medicine, especially for targeting very small tumor masses such as metastases (Tavares and Tavares, 2010; Thisgaard et al., 2016; Grudzinski et al., 2018).

57

The utility of Auger radionuclides in therapy is believed to hinge on their photon-to-electron energy yield, or "p/e ratio" (Bernhardt et al., 2001). Since photons deposit most of their energy in healthy tissues away from small targets, their dose contribution is typically unwanted in Auger therapy. Therefore, a p/e ratio as low as possible is generally considered desirable. Rhodium-103m ( $\left.{ }^{103 \mathrm{~m}} \mathrm{Rh}, \mathrm{T} 1 / 2=56.11 \mathrm{~min}\right)$ decays via isomeric transition to stable ${ }^{103} \mathrm{Rh}$, giving rise to the emission of Auger electrons (figure 1). The decay of ${ }^{103 \mathrm{~m}} \mathrm{Rh}$ distinguishes itself by having a high Auger electron yield compared to its emissions of photons (Xrays). ${ }^{103 \mathrm{~m}} \mathrm{Rh}$ emits about 29 times as many low energy (<40 keV) electrons as photons (2-40 keV) per decay, including a 150\% intensity emission of a $0.39 \mathrm{keV}$ Auger electron (Bernhardt et al., 2001; NuDat2). Adjusted for the energies of the emissions, this gives a p/e ratio of 0.04 , making ${ }^{103 \mathrm{~m}} \mathrm{Rh}$ one of the most promising radionuclides for Auger radiotherapy, as was suggested by Bernhardt et al. (Bernhardt et al., 2001).

$\mathrm{Rh}$ (III) can be chelated by sulfur-based macrocycles (Lyczko et al., 2017) and ${ }^{103 \mathrm{~m}} \mathrm{Rh}$ is thus potentially relevant in radiopharmaceutical applications. ${ }^{103 \mathrm{~m}} \mathrm{Rh}$ can be obtained as the daughter radionuclide from both the decay of ${ }^{103} \mathrm{Ru}$ and ${ }^{103} \mathrm{Pd} .{ }^{103} \mathrm{Ru}(\mathrm{T} 1 / 2=39.25$ days) can be produced by the fission of uranium 
followed by separation through distillation or solvent extraction (Bernhardt et al., 2001), as well as by neutron irradiation of enriched ${ }^{102} \mathrm{Ru}$. A solution-based generator system for supplying ${ }^{103 \mathrm{~m}} \mathrm{Rh}$ from ${ }^{103} \mathrm{Ru}$ was described by Skarnemark and co-workers (Bartoś et al., 2009; Skarnemark et al., 2009). Using a series of extractions, oxidations and evaporations, they reported being able to obtain ${ }^{103 \mathrm{~m}} \mathrm{Rh}$ in high radiochemical purity. ${ }^{103} \mathrm{Ru}$ has the drawbacks of being a beta $\left(E_{\text {mean }}=64.1 \mathrm{keV}, 92 \%\right)$ and gamma $(E=497 \mathrm{keV}, 91 \%)$ emitter. These decay properties mean that the presence of small amounts of ${ }^{103} \mathrm{Ru}$ in the eluted ${ }^{103 \mathrm{~m}} \mathrm{Rh}$ would limit the advantageous dosimetry of Auger radiotherapy significantly and also make efficient shielding of the generator necessary, both during preparation and storage, as was pointed out by Skarnemark et al. (Skarnemark et al., 2009). ${ }^{103} \mathrm{Pd}$ decays to ${ }^{103 \mathrm{~m}} \mathrm{Rh}$ through electron capture with a half-life of 17 days (figure 1). Besides abundant Auger electrons, ${ }^{103} \mathrm{Pd}$ emits only X-ray photons in the 20-23 keV range (77\%). This allows for fairly non-problematic shielding, handling, storage and elution of a ${ }^{103} \mathrm{Pd}$ based generator. Further, ${ }^{103} \mathrm{Pd}$ already enjoys widespread medical use by virtue of its $\mathrm{X}$-ray emissions, utilized in brachytherapy (Ferro et al., 2018). This makes a potential generator of ${ }^{103 \mathrm{~m}} \mathrm{Rh}$ from ${ }^{103} \mathrm{Pd}$ desirable. Skarnemark and co-workers also reported a solution-phase generator of ${ }^{103 \mathrm{~m}} \mathrm{Rh}$ from neutron irradiated ${ }^{\text {nat }} \mathrm{PdCl}_{2}$ or ${ }^{\text {nat }} \mathrm{Pd}(\mathrm{NO})_{3}$ (Skarnemark et al., 2009). The group mentioned that the system was in the early stages of development with limited detail provided, but unfortunately no further reports have emerged in the literature.

Production of ${ }^{103} \mathrm{Pd}$ from stable ${ }^{103} \mathrm{Rh}$ using a cyclotron has been reported, mainly through the ${ }^{1038} \mathrm{Rh}(p, n){ }^{103} \mathrm{Pd}$ reaction (Sudar, 2002, IAEA, 2009). However, this approach requires the dissolution of highly inert solid Rh targets, which can be challenging in research laboratories. A simpler and less laborious way of obtaining ${ }^{103} \mathrm{Pd}$ is via neutron irradiation of ${ }^{102} \mathrm{Pd}$ enriched $\mathrm{Pd}$ targets. This allows the facile dissolution of the target in aqua regia, eventually furnishing a solution of $\left[{ }^{103} \mathrm{Pd}\right] \mathrm{PdCl}_{2}$. In order to obtain high quantities of ${ }^{103} \mathrm{Pd}$, it is also possible to irradiate silver targets with high energy and high intensity proton beams (Fassbender, 1999). The multiple methods for production of ${ }^{103} \mathrm{Pd}$ on both research scale and industrial scale make the ${ }^{103 \mathrm{~m}} \mathrm{Rh} /{ }^{103} \mathrm{Pd}$ generator a promising system for Auger-based radiotherapy. In this report we demonstrate the feasibility of a generator system for ${ }^{103 \mathrm{~m}} \mathrm{Rh}$ based on chelated low specific activity ${ }^{103} \mathrm{Pd}$ trapped on a solid phase support contained within a plastic cartridge. The expulsion of ${ }^{103 \mathrm{~m}} \mathrm{Rh}$ that we observed was hypothesized to derive from a combination of the Szilard-Chalmers effect and ionization from the decay. This allowed the elution of ${ }^{103 \mathrm{~m}} \mathrm{Rh}$ in dilute aqueous hydrochloric acid in very high radiochemical purity. The reported generator allows the direct use of neutron irradiated ${ }^{102} \mathrm{Pd}$ enriched foils, which is arguably the simplest way of preparing ${ }^{103} \mathrm{Pd}$. Further, being a cartridge contained generator, the use of toxic organic solvents was avoided and the handling was simple and practical. 


\section{EXPERIMENTAL}

\subsection{Materials}

Unless otherwise stated, chemicals (including 5) were purchased from Sigma-Aldrich and used without further purification. Solvents were purchased from VWR in ACS reagent/Ph. Eur. Analytical Reagent grade (AnalaR NORMAPUR ${ }^{\circledR}$ ), unless otherwise noted. Ultrapure water was used in all cases (Milli-Q water purification system, Millipore, USA). Sep-Pak Plus C18 (short, $360 \mathrm{mg}$ ) cartridges were purchased from Waters (USA). Ultima Gold scintillation liquid was from Perkin Elmer (USA). LSC analyses were performed on a Hidex $300 \mathrm{SL}$ liquid scintillator in normal double coincidence mode from Hidex, (Finland). Radioactivities were measured on an LGC-5 high purity germanium (HPGe) detector from Princeton Gamma-Tech (USA). Radio-TLCs were run on Merck aluminum-backed silica plates and analyzed on a Cyclone Plus Storage Phosphor System from Perkin Elmer (USA). X-ray spectra were measured on a Canberra HPGe X-ray detector from Mirion Technologies/Canberra (USA). NMR spectra were recorded on a Varian/Agilent $400 \mathrm{MR}$ operating at $400.445 \mathrm{MHz}(1 \mathrm{H})$ from Agilent Technologies (USA).

\subsection{Neutron irradiation of ${ }^{102} P d$ enriched $P d$ foils}

Transmutation of ${ }^{102} \mathrm{Pd}$ to ${ }^{103} \mathrm{Pd}$ was carried out in a high thermal neutron flux. ${ }^{102} \mathrm{Pd}$ enriched (77.9\%) palladium foils (Oak Ridge National Labs, batch 191001) were sealed in high purity quartz ampoules (Heraeus Suprasil). The ampoules were irradiated in the high-flux irradiation position V4 of the European high-flux reactor operated by Institut Laue-Langevin in Grenoble, France. One Pd foil (A, $0.30 \mathrm{mg} P d)$ was irradiated for 7.73 days in a thermal neutron flux of $\approx 1.2 \cdot 10^{15} \mathrm{n} \cdot \mathrm{cm}^{-2} \mathrm{~s}^{-1}$. A second Pd foil (B, $0.48 \mathrm{mg} P d$ ) was irradiated over two periods with an intermittent break of 2.8 days. First irradiation: 4.44 days in a thermal neutron flux of $\approx 1.2 \cdot 10^{15}$ n.cm $\mathrm{cm}^{-2}$, second irradiation: 2.74 days in a thermal neutron flux of $\approx 1.4 \cdot 10^{15} \mathrm{n} \cdot \mathrm{cm}^{-2} \mathrm{~s}^{-1}$.

\subsection{Quantification of ${ }^{103} \mathrm{Pd}$ by gamma spectroscopy}

136 The activity of ${ }^{103} \mathrm{Pd}$ was determined using a Ge(Li) detector (Princeton Gammatech) with 10\% efficiency. 137 Samples were measured in aqueous media in volumes up to about $1 \mathrm{~mL}$ in glass vials or Eppendorf tubes. 
138

139

140

141

142

143

144

145

146

147

148

149

150

151

152

153

154

155

156

157

158

159

160

161

162

163

164

165

166

167

168

169

Samples were placed at a distance of $20 \mathrm{~cm}$ from the detector. The detector had been energy and efficiency calibrated using traceable AEA gamma reference sources of ${ }^{133} \mathrm{Ba}$ and ${ }^{152} \mathrm{Eu}$ (AEA Technology QSA $\mathrm{GmbH}$, Germany). Spectra were analyzed using the Genie-2000 software package (Version 3.2.1., Canberra Industries). Gamma peak areas were efficiency corrected and the ${ }^{103} \mathrm{Pd}$ activity of the samples was determined as a counting-statistics weighted average of the radioactivities determined from the following well-known low yield gamma lines of ${ }^{103} \mathrm{Pd}$ : $294.98 \mathrm{keV}(0.0028 \%), 357.45 \mathrm{keV} \quad$ (0.0221\%), $497.08 \mathrm{keV}$ (0.0040\%), energies and yields from NuDat 2.7 (NuDat2).

\subsection{Preparation of $\left[{ }^{103} \mathrm{Pd}\right] \mathrm{PdCl}_{2}$ solution in $\mathrm{HCl}$ from irradiated $\left[{ }^{102} \mathrm{Pd}\right] \mathrm{Pd}$}

To the irradiated Pd foils (A: $0.30 \mathrm{mg}, \mathrm{B}: 0.48 \mathrm{mg}$ ) was added aqua regia $(1.0 \mathrm{~mL})$, freshly prepared by mixing conc. $\mathrm{HCl}$ (37\%, 3 parts) with conc. $\mathrm{HNO}_{3}(65 \%, 1$ part). After about 1 hour, the metal was dissolved and the mixture was evaporated to dryness at $130{ }^{\circ} \mathrm{C}$ under a stream of nitrogen for 10 minutes. The dry residue was dissolved in conc. $\mathrm{HCl}(500 \mu \mathrm{L})$ and evaporated to dryness at $130{ }^{\circ} \mathrm{C}$ under a stream of nitrogen for 5-10 minutes. Dissolution in conc. $\mathrm{HCl}$ and evaporation to dryness was repeated two more times to furnish dry $\left[{ }^{103} \mathrm{Pd}\right] \mathrm{PdCl}_{2}$. This was dissolved in aq. $\mathrm{HCl}(500 \mu \mathrm{L}, 10 \mathrm{mM})$ and filtered through a syringe mounted frit. The frit was washed with a further aliquot of aq. $\mathrm{HCl}(500 \mu \mathrm{L}, 10 \mathrm{mM})$. This yielded a total volume of $1.0 \mathrm{~mL}$ containing $\left[{ }^{103} \mathrm{Pd}\right] \mathrm{PdCl}_{2}(\mathrm{~A}: 276 \pm 5 \mathrm{MBq}, \mathrm{B}: 539 \pm 6.9 \mathrm{MBq})$.

\subsection{Synthesis of 16aneS4-O-octyl (3), scheme 1}

Under an argon atmosphere, methanesulfonyl chloride $(724 \mu \mathrm{L}, 9.53 \mathrm{mmol})$ was added to a solution of octanol $(1.0 \mathrm{~mL}, 6.4 \mathrm{mmol})$ and triethylamine $(2.7 \mathrm{~mL}, 19 \mathrm{mmol})$ in anhydrous dichloromethane $(20 \mathrm{~mL})$ and the mixture was stirred at room temperature for 3.5 hours. When TLC (hexane-ethyl acetate, 8:2) indicated a complete consumption of the starting material, the reaction mixture was added to a separations funnel containing aq. $\mathrm{HCl}(100 \mathrm{~mL}, 1.0 \mathrm{M})$ and hexane-ethyl acetate $(3: 1,100 \mathrm{~mL})$. The aqueous phase was removed and the organic phase was washed twice with water $(2 \times 100 \mathrm{~mL})$, dried over $\mathrm{NaSO}_{4}$, filtered and evaporated to dryness, yielding compound 1 as a colorless oil, pure by ${ }^{1} \mathrm{H}-\mathrm{NMR}(1.32 \mathrm{~g}, 99 \%), \mathrm{R}_{\mathrm{f}}=0.54 .{ }^{1} \mathrm{H}$ $\operatorname{NMR}\left(400 \mathrm{MHz}, \mathrm{CDCl}_{3}\right): \delta 4.23(\mathrm{t}, J=6.7 \mathrm{~Hz}, 2 \mathrm{H}), 3.01(\mathrm{~s}, 3 \mathrm{H}), 1.75(\mathrm{~m}, 2 \mathrm{H}), 1.39(\mathrm{~m}, 2 \mathrm{H}), 1.31(\mathrm{~m}, 8 \mathrm{H}), 0.89$ $(\mathrm{t}, J=10.2 \mathrm{~Hz}, 3 \mathrm{H}) .{ }^{13} \mathrm{C}-\mathrm{NMR}\left(100 \mathrm{MHz}, \mathrm{CDCl}_{3}\right): \delta 70.18,37.35,31.69,29.11,29.05,28.96,25.40,22.59$, 14.05 (see S.I. for NMR spectra). 
Compound $\mathbf{2}$ was prepared according to previously published procedures, using the Ziegler influxtion technique (Li et al., 1997, Copper et al. 1996). In brief, 4,8-dithiaundecane-1,11-dithiol was mixed with 1,3dichloro-2-propanol in DMF, and added slowly to a mixture of DMF and cesium carbonate in excess, heated to $80{ }^{\circ} \mathrm{C}$. We obtained the final product in excellent purity and $43 \%$ yield. ${ }^{1} \mathrm{H} \mathrm{NMR}\left(400 \mathrm{MHz}, \mathrm{CDCl}_{3}\right) \delta 3.91-$ $3.83(\mathrm{~m}, 1 \mathrm{H}), 2.90-2.62(\mathrm{~m}, 16 \mathrm{H}), 1.98-1.86(\mathrm{~m}, 6 \mathrm{H}) .{ }^{13} \mathrm{C}-\mathrm{NMR}\left(100 \mathrm{MHz}, \mathrm{CDCl}_{3}\right): \delta 68.90,38.28,31.04$, 30.94, 30.88, 29.78, 29.49. MS (MALDI-TOF, DHB NaCl): $\mathrm{M}+\mathrm{Na}+\mathrm{H}$ found 335.32 (Calculated $\mathrm{C}_{12} \mathrm{H}_{23} \mathrm{NaOS}_{4}$ exact mass: 335.05) (see S.I. for NMR spectra).

Under an argon atmosphere, a flame-dried flask was charged with sodium hydride in mineral oil (60\%, 11 $\mathrm{mg}, 0.28 \mathrm{mmol}), 2(52 \mathrm{mg}, 0.17 \mathrm{mmol})$, toluene $(2.0 \mathrm{~mL}$ ) and anhydrous DMF (1.0 DMF). A solution of 1 (67 $\mathrm{mg}, 0.32 \mathrm{mmol})$ in toluene $(1.0 \mathrm{~mL})$ was added and the resulting mixture was stirred under argon at $70{ }^{\circ} \mathrm{C}$ for 6 hours, then transferred to a separation funnel containing EtOAc $(50 \mathrm{~mL})$ and water $(50 \mathrm{~mL})$. The aqueous phase was discarded and the organic phase was washed once with water $(50 \mathrm{~mL})$, then dried over $\mathrm{NaSO}_{4}$ and rotary evaporated to dryness. The crude mixture was purified by flash chromatography in Hexane-EtOAc (95:5) furnishing the desired compound 3 as a colorless amorphous solid (28 mg, 40\%). $R_{f}=$ 0.24 (hexane/ethyl acetate, 95:5). ${ }^{1} \mathrm{H}-\mathrm{NMR}\left(400 \mathrm{MHz}, \mathrm{CDCl}_{3}\right): \delta 4.23(\mathrm{t}, J=6.7 \mathrm{~Hz}, 2 \mathrm{H}), 3.01(\mathrm{~s}, 3 \mathrm{H}), 1.75(\mathrm{~m}$, $2 \mathrm{H}), 1.39(\mathrm{~m}, 2 \mathrm{H}), 1.31(\mathrm{~m}, 8 \mathrm{H}), 0.89(\mathrm{t}, J=10.2 \mathrm{~Hz}, 3 \mathrm{H}) .{ }^{13} \mathrm{C}-\mathrm{NMR}\left(100 \mathrm{MHz}, \mathrm{CDCl}_{3}\right): \delta$ 70.18, 37.35, 31.69, 29.11, 29.05, 28.96, 25.40, 22.59, 14.05. MS (MALDI-TOF, DHB NaCl): M+Na found 447.49 (Calculated $\mathrm{C}_{20} \mathrm{H}_{40} \mathrm{NaOS}_{4}$ exact mass: 447.19) (see S.I. for NMR spectra).

\subsection{Preparation and elution of generator}

To a glass HPLC vial $(1.5 \mathrm{~mL}, \mathrm{VWR})$ was added acetonitrile $(305 \mu \mathrm{L}),\left[{ }^{103} \mathrm{Pd}\right] \mathrm{PdCl}_{2}$ in aq. $\mathrm{HCl}(10 \mathrm{mM}, 90 \mu \mathrm{L}$, $10.1 \mathrm{MBq}, 27 \mu \mathrm{g} \mathrm{Pd}, 0.25 \mu \mathrm{mol} \mathrm{Pd})$ and a solution of 3 in acetonitrile $(54 \mu \mathrm{L}, 10 \mathrm{mg} / \mathrm{mL}, 0.54 \mathrm{mg}, 1.26$ $\mu \mathrm{mol})$. The mixture was heated at $80{ }^{\circ} \mathrm{C}$ for 125 minutes, then cooled to room temperature. The faintly yellow solution was analyzed by radio-TLC ( $5 \%(\mathrm{w} / \mathrm{v}) \mathrm{NH}_{4} \mathrm{OAc}$ in $\left.\mathrm{H}_{2} \mathrm{O}-\mathrm{MeOH}, 1: 1\right)$ with UV-VIS and $\mathrm{KMnO}_{4}$ staining, and the quantitative formation of the desired radioactive compound (4) was confirmed as a single peak at $R_{f}$ 0.1. To the mixture was then added water $(750 \mu \mathrm{L})$, which caused slight precipitation of very fine particles. The mixture was aspirated into a syringe and applied to a C18 Sep Pak Plus, which had been pretreated with water $(10 \mathrm{~mL})$, with the immediately passing liquid collected as Fraction 0 . The generator was then washed through with water $(2 \times 5.0 \mathrm{~mL})$ as Fractions 1 and 2 . The prepared generator was subsequently eluted by passing through $1.0 \mathrm{~mL}$ of either aq. $\mathrm{HCl}(1.0 \mathrm{M}$ or $0.01 \mathrm{M})$ or aq. $\mathrm{HCl}(1.0 \mathrm{M})$ mixed 
with $5 \%$ acetonitrile $(\mathrm{v} / \mathrm{v})$. After elution of the generator with aq. $\mathrm{HCl}(1.0 \mathrm{~mL}, 1.0 \mathrm{M})$, an aliquot of the eluate $(0.10 \mathrm{~mL})$ was removed for counting on a liquid scintillation counter.

\subsection{Analysis of eluates by liquid scintillation (LSC)}

An aliquot of the "undiluted eluate" (UE, $50 \mu \mathrm{L})$ was mixed with aq. $\mathrm{HCl}(1.0 \mathrm{M}, 950 \mu \mathrm{L})$ for a 1:20 dilution ("diluted eluate", DE). To five scintillation vials containing Ultima Gold scintillation cocktail (10 mL) was then added either of the DE: $2 \mu \mathrm{L}$ (\#1), $20 \mu \mathrm{L}$ (\#2), $200 \mu \mathrm{L}$ (\#3) or of the UE: $20 \mu \mathrm{L}(\# 4), 200 \mu \mathrm{L}(\# 5)$. The vials were manually stirred until a clear solution was obtained. The vials were counted for 10 minutes without energy discrimination. A blank sample was co-counted in all cases to establish the background, which was subtracted from the measurements. All ${ }^{103} \mathrm{Pd}$ quantifications lay within the linear area of a prepared standard curve (see supplementary information S1).

\subsection{Analysis of eluates by X-ray detection}

On each sample, X-ray spectrometry measurements were performed within four hours after elution on 100 $\mu \mathrm{L}$ of the eluate. A final measurement was performed 2 to 5 days later, after decay of the initial ${ }^{103 m} \mathrm{Rh}$ activity, to determine the amount of ${ }^{103} \mathrm{Pd}$ breakthrough. The detector efficiency at $20.1 \mathrm{keV}$ was determined by linear interpolation of the measured efficiencies of the $13.9 \mathrm{keV}$ and $26.3 \mathrm{keV}$ lines of a certified ${ }^{241} \mathrm{Am}$ calibration source measured in the same geometry as the subsequent samples. Measurements were done in flat-bottomed thin-walled plastic vials. By first establishing the breakthrough using the measurement performed after 2 to 5 days, the counts stemming from ${ }^{103} \mathrm{Pd}$ breakthrough could be subtracted from the measurements at other time-points, to enable correct calculation of ${ }^{103 \mathrm{~m}} \mathrm{Rh}$ activity. The initial activity present at the time of elution could then be calculated from equation 1.

where $A_{0}$ is the ${ }^{103 m} R h$ activity at the time of elution, $t_{1}$ and $t_{2}$ are the time of measurement start and end, respectively, eff is the detector efficiency at $20.1 \mathrm{keV}, \mathrm{I}_{\mathrm{x}-\text { ray }}$ is the combined intensity of the $20.074 \mathrm{keV}$ and $20.216 \mathrm{keV}^{103 \mathrm{~m}} \mathrm{Rh} \mathrm{x}$-rays and $\lambda$ is the ${ }^{103 \mathrm{~m}} \mathrm{Rh}$ decay constant. 


\section{RESULTS}

$\left[{ }^{103} \mathrm{Pd}\right] \mathrm{PdCl}_{2}$ was obtained as radioactive metal foils by neutron irradiation. The foils were easily dissolved in fresh aqua regia, which was subsequently removed by evaporation. This was followed by three cycles of aq. $\mathrm{HCl}$ additions and evaporations to dryness to remove the nitric acid and furnish $\left[{ }^{103} \mathrm{Pd}\right] \mathrm{PdCl}_{2}$ as a solution in aq. $\mathrm{HCl}(10 \mathrm{mM})$. A final filtration step was necessary to remove a small amount of visible, undissolved black particles. The total processing led to only limited loss of activity of about $5 \%$. $\left[{ }^{103} \mathrm{Pd}\right] \mathrm{PdCl}_{2}$ solutions were obtained with molar radioactivities in the range of $98-120 \mathrm{MBq} / \mu \mathrm{mol}$. In order to prepare the generator, 16aneS4 chelator derivatives were purchased (16aneS4, compound 5) or synthesized (compounds 2, $\mathbf{3}$ and 5, for NMR spectra, see supplementary information S2). This macrocyclic ring is known to chelate Pd as well as Rh. In order to chelate all the Pd present, the chelators were added to the $\left[{ }^{103} \mathrm{Pd}\right] \mathrm{PdCl}_{2}$ in a 5-fold excess. Initially, the un-modified 16aneS4 (5) was used, but the resulting Pd-16aneS4 chelate was not retained on the C18 cartridge. Therefore, a 16aneS4 derivative modified with a strongly lipophilic n-octyl chain (3) was synthesized. The chelation of the $\left[{ }^{103} \mathrm{Pd}\right] \mathrm{Pd}$ by $\mathbf{3}$ to form $\mathbf{4}$ was carried out in a mixture of $10 \mathrm{mM} \mathrm{HCl}$ and acetonitrile (1:4), in order for the chelator to stay in solution. After heating to $80{ }^{\circ} \mathrm{C}$ for 90 minutes, the activity was seen on radio-TLC (5\% aq. $\left.\mathrm{NH}_{4} \mathrm{OAc}: \mathrm{MeOH}, 1: 1\right)$ to shift from a broad smear at $R_{f}$ 0.0-0.35 to a well-defined peak at $R f=0.08-0.09$ (RCP: 98.5\%). This radioactive peak was also visible on both UV-VIS and $\mathrm{KMnO} 4$ stain, indicating the formation of a metal complex. To increase the polarity of the mixture, water was added to an acetonitrile concentration of $30 \%(\mathrm{v} / \mathrm{v})$. This led to a slight, almost opalescent precipitation in the mixture, upon which the entire volume was led through a C18 plus Sep-Pak cartridge, catching about $71 \%$ of the total activity on the support. The remaining activity eluted through in Fraction 0 (13\%) and Fraction 1 (20\%). Fraction 2 did not contain enough ${ }^{103} \mathrm{Pd}$ to be detectable on the HPGe detector. The initial breakthrough of about $30 \%$ of the activity in fraction 0 and fraction 1 suggests that the polarity of the water-acetonitrile reaction mixture and the lipophilicity of $\mathbf{3}$ were not

The prepared generator, containing the retained $\left[{ }^{103} \mathrm{Pd}\right] \mathbf{4}$ was eluted with dilute hydrochloric acid. We found no noticeable difference between using $1.0 \mathrm{M}$ and $0.1 \mathrm{M} \mathrm{HCl}$. The eluates $(1.0 \mathrm{~mL})$ were analyzed by liquid scintillation in order to assess elution yield and ${ }^{103} \mathrm{Pd}$ breakthrough (figure 2). The liquid scintillation counting efficiencies for ${ }^{103} \mathrm{Pd}$ was determined by preparing a ${ }^{103} \mathrm{Pd}$ standard curve and comparing scintillation counts with gamma spectroscopy (see supplementary information S1). Because of ${ }^{103 m} \mathrm{Rh}$ ingrowth, LSC counting to obtain ${ }^{103} \mathrm{Pd}$ activities was performed only after the two nuclides reached secular 
equilibrium in any sample (typically 10 hours after any separation procedure). Therefore, LSC count rates for ${ }^{103} \mathrm{Pd}$ samples were a factor of 1.1 higher than the decay rates determined by gamma spectroscopy, owing to co-detection of ${ }^{103 \mathrm{~m}} \mathrm{Rh}$ decay.

To establish the counting efficiency for ${ }^{103 \mathrm{~m}} \mathrm{Rh}$ on the LSC, eluate samples were also analyzed by X-ray detection. In an example measurement, the total eluted ${ }^{103 \mathrm{~m}} \mathrm{Rh}$ activity was calculated by $\mathrm{X}$-ray detection to be $146 \pm 4 \mathrm{kBq}$ with a breakthrough of $1.04 \pm 0.02 \mathrm{kBq}$ of ${ }^{103} \mathrm{Pd}$ corresponding to $0.71 \pm 0.02 \%$ of the total eluted activity. The same eluate was also analyzed in triplicate by LSC, where ${ }^{103} \mathrm{Pd}$ breakthrough deducted counts of $85.2 \pm 0.6 \mathrm{kcps}$ were obtained. Through a range of such measurements, the LSC was observed to detect ${ }^{103 m}$ Rh at an efficiency of $51 \pm 4 \%(n=9)$, and LSC counts in cps were corrected with a factor of 1.98 to obtain ${ }^{103 \mathrm{~m}} \mathrm{Rh}$ radioactivities.

Eluates from the generator were analyzed by LSC, in order to assess ${ }^{103 \mathrm{~m}} \mathrm{Rh}$ elution yields and ${ }^{103} \mathrm{Pd}$ breakthrough. Eluates were diluted to 5 different concentrations and analyzed by counting 20 times, each an hour apart. After about 10 hours of counting, a stable plateau was reached (figure 2). This plateau was caused by the presence of slowly decaying ${ }^{103} \mathrm{Pd}$, as had been demonstrated by X-ray spectrometry. The plateau cps, as well as the background counts, were subtracted from the remaining counts and the data was fitted by chi-square minimization to an exponential decay, with the initial count rate and the half-life as floating parameters. The counts were then converted to radioactivities using the factors given above. The obtained data are presented in table 1. It was found that after subtraction of background and ${ }^{103} \mathrm{Pd}$ plateau activity, the decay of the remaining activity corresponded well with literature values for the half-life of ${ }^{103 \mathrm{~m}} \mathrm{Rh}$ of $56.11 \mathrm{~min}$ (NuDat2). That these counts were indeed stemming from the detection of ${ }^{103 \mathrm{~m}} \mathrm{Rh}$ decays was further supported by the observed X-ray spectrum (figure $\mathbf{3}$ ).

Initially, the generator was eluted with dilute aq. $\mathrm{HCl}(1.0 \mathrm{M})$. This resulted in a decay-corrected ${ }^{103 \mathrm{~m}} \mathrm{Rh}$ yield of $5.81 \pm 0.14 \%(n=3)$. This yield was calculated as the eluted ${ }^{103 m}$ Rh activity as a percentage of the ${ }^{103} \mathrm{Pd}$ activity retained on the generator before elution (the theoretical maximum). The co-elution of ${ }^{103} \mathrm{Pd}$ was found to be relatively modest, with about $0.4 \%$ of the eluted activity stemming from ${ }^{103} \mathrm{Pd}$. This made up $0.02 \%$ of the total ${ }^{103} \mathrm{Pd}$ retained on the cartridge, amounting to very limited ${ }^{103} \mathrm{Pd}$ breakthrough. Accordingly, the radiochemical purity (RCP) of the eluted ${ }^{103 m} \mathrm{Rh}$ was excellent at around $99.6 \%$. It should be noted that this is an estimated RCP. No other radioactive species were observed in the eluates by gamma spectroscopy, X-ray spectroscopy or LSC, but long-term, high sensitivity measurements were not done. The eluted breakthrough of $\left[{ }^{103} \mathrm{Pd}\right] \mathrm{Pd} *$ was observed by radio-TLC to be from multiple species, and not solely 
from co-eluted 4 (see supplementary information S3). To underscore this fact, eluted palladium is written with an asterisk, as $\left[{ }^{103} \mathrm{Pd}\right] \mathrm{Pd}^{*}$. Elution of the generator with $0.1 \mathrm{M}$ aq. $\mathrm{HCl}$ was also tested. This resulted in a similar ${ }^{103 \mathrm{~m}} \mathrm{Rh}$ yield (5.8\%) but a slightly higher co-elution of $\left[{ }^{103} \mathrm{Pd}\right] \mathrm{Pd}{ }^{*}$ resulting in a lower effective molar activity. It was hypothesized that the relatively modest ${ }^{103 \mathrm{~m}} \mathrm{Rh}$ yield eluted from the generator could be because of insufficient wetting of the $\mathrm{C} 18$ support by the purely aqueous eluents, causing a significant amount of released ${ }^{103 \mathrm{~m}} \mathrm{Rh}$ to stay behind. To remedy this, the generator was eluted with a mixture of $1.0 \mathrm{M}$ aq. $\mathrm{HCl}$ and acetonitrile (95:5). Indeed, the result was a slightly higher ${ }^{103 \mathrm{~m}} \mathrm{Rh}$ yield $(7.60 \pm 0.12 \%)$ but the co-eluted $\left[{ }^{103} \mathrm{Pd}\right] \mathrm{Pd}$ * was also significantly higher, with a breakthrough of $0.07 \%$. This caused the effective molar activity of the obtained ${ }^{103 \mathrm{~m}} \mathrm{Rh}$ to be more than halved when compared to using $1.0 \mathrm{M} \mathrm{HCl}$ only.

\section{DISCUSSION}

With this report, we demonstrate the feasibility of a solid-phase generator system for ${ }^{103 \mathrm{~m}} \mathrm{Rh}$ from chelated ${ }^{103} \mathrm{Pd}$. The desirability of such a generator system, although in their example based on ${ }^{103} \mathrm{Ru}$, was recently stated by Fassbender and co-workers (Mastren et al., 2017). The tendency of a decaying radionuclide to break free from the molecule of which it forms part is known as the Szilard-Chalmers effect. This occurs due to the recoil resulting from the decay emissions. The phenomenon is especially interesting in the radiopharmaceutical use of radiometal chelates with radioactive daughters. Here, the decay of the parent may expel the daughter from the chelator, resulting in a free radioactive species with its own pharmacokinetics (Edem et al., 2016; Severin et al., 2017; Kozempel, 2018). The effect has also been utilized for the preparation of radionuclide generators. By taking advantage of the different chemical properties of the chelated parent and the free daughter, separation is possible. In this case, the parent is rendered lipophilic through confinement by an organic molecule, and can then be trapped on a solid C18 support. Upon decay and expulsion from the chelate, the now free hydrophilic daughter radionuclide can be eluted with an appropriate aqueous solution. This makes separation possible, even when the chemical separation of the two corresponding free metal ions is very difficult. In this report, we employed the Szilard-Chalmers generator principle to release ${ }^{103 \mathrm{~m}} \mathrm{Rh}$ from chelated ${ }^{103} \mathrm{Pd}$ that was trapped on a solid support. Using a lipophilic derivative of the 16 aneS4 chelator, $\left[{ }^{103} \mathrm{Pd}\right] \mathrm{Pd}$ was retained on a $\mathrm{C} 18$ solid support, and ${ }^{103 \mathrm{~m}} \mathrm{Rh}$ could be eluted in dilute hydrochloric acid. Zeevaart and co-workers reported calculations that the expulsion of ${ }^{103 \mathrm{~m}} \mathrm{Rh}$ by recoil from a $\left[{ }^{103} \mathrm{Pd}\right] \mathrm{Pd}$-chelate was highly unlikely, due to the low energy released in the decay (Rooyen, Szucs and Rijn, 2008; Zeevaart et al., 2012). As the authors pointed out, chemical differences between parent and daughter cannot be relied on for expulsion, since Rh is also chelated by 16aneS4. However, we hypothesized that the strong ionization of the atom that occurs 
through the emission of the Auger electrons provides a temporary, profound change in the electronic structure which may lead to expulsion. In this report, we have provided evidence that the expulsion of ${ }^{103 \mathrm{~m}} \mathrm{Rh}$ from a $\left[{ }^{103} \mathrm{Pd}\right] \mathrm{Pd}$-16aneS4 chelate is indeed possible, which may be attributed to this transitory ionization of the daughter. We observed an elution yield on the order of $6 \%$. Although a slightly less polar eluent was shown to increase the yield, it did not change to any significant degree. This may be an indication that the expulsion reaction is not entirely efficient and that some amount of the generated ${ }^{103 \mathrm{~m}} \mathrm{Rh}$ stays associated with the chelator. This lends support to the calculations by Zeevaart \& co-workers, while at the same time demonstrating that some degree of expulsion does take place. Since we routinely used a chelator-to-Pd ratio of 5 , expelled ${ }^{103 \mathrm{~m}} \mathrm{Rh}$ could also enter empty chelators present in the generator. However, chelation of $\mathrm{Rh}(\mathrm{III})$ by $16 a n e S 4$ is typically done at elevated temperature, with optimal conditions for quantitative incorporation reported by Venkatesh et al. (Venkatesh 1996) to be 1 hour at $80{ }^{\circ} \mathrm{C}$ and pH 4 , with an ethanol presence over $10 \%$. These conditions are very different from the ones present in the generator, and the produced ${ }^{103 \mathrm{~m}} \mathrm{Rh}$ is only present for a short time, given its decay half-life. Further, the $16 a n e S 4$ chelator is in any case present in a very large excess $\left(>10^{7}\right)$ relative to the sub-nanomolar ${ }^{103 \mathrm{~m}} \mathrm{Rh}$, so that even a 10 -fold decrease in the amount of the 16 aneS4 is expected to have a negligible effect on the complexation equilibrium. Finally, increasing the wetting of the C18 support by using a higher amount of organic co-solvent during elution may also increase the yield. A requirement for such a strategy would be a thorough optimization of the lipophilic chelator derivate that would allow it to be fully retained on the support. A strategy for this could be increasing the size of the lipophilic substituent.

The co-elution of $\left[{ }^{103} \mathrm{Pd}\right] \mathrm{Pd} \mathrm{d}^{*}$ was limited but still significant. The relatively low dose deposition from the Xrays and gammas from very small amounts of ${ }^{103} \mathrm{Pd}$ does not represent an issue in regards to Auger therapy, as was pointed out by Bernhardt et al. (Bernhardt et al., 2001). However, it does have an effect of the specific activity of the generated ${ }^{103 \mathrm{~m}} \mathrm{Rh}$. Depending on elution medium, we obtained apparent molar activities of ${ }^{103 \mathrm{~m}} \mathrm{Rh}$ in the range of around $10-30 \mathrm{MBq} / \mathrm{nmol} \mathrm{Pd}$, decay-corrected to the time of dissolution of the $\left[{ }^{103} \mathrm{Pd}\right] \mathrm{Pd}$ foil. Note the fact that this molar activity was calculated in relation to Pd, not Rh, since the $\mathrm{Pd}$ content will be the factor interfering with radiolabeling. Of high relevance for the final specific activity of the ${ }^{103 \mathrm{~m}} \mathrm{Rh}$ product, is the initial ${ }^{103} \mathrm{Pd}$ specific activity of the irradiated foil. We irradiated $77.9 \% \mathrm{Pd}-102$ enriched foils (Oak Ridge National Labs, batch 191001) for 7-8 days, but obtained only about $43 \%$ of the expected theoretical yield at irradiation. With transport from ILL (Grenoble, France) to reception and treatment at DTU Nutech (Roskilde, Denmark), lasting 17 days, the available activity was only $21 \%$ of the theoretical maximum. Accordingly, with an irradiation resulting in a higher transmutation yield in the vicinity of the theoretical maximum, and processing closer to the end of irradiation, apparent molar 
activities of about a factor 5 higher can be obtained. This would give a maximum apparent molar activity of more than $100 \mathrm{MBq} / \mathrm{nmol} \mathrm{Pd}$, which is well-suited for radiolabeling receptor-specific tracers. Higher specific activity may be obtained by using targets with higher ${ }^{102} \mathrm{Pd}$ enrichment (>96\%) and longer irradiation times.

At the moment, ${ }^{103} \mathrm{Pd}$ is not easily available for research needs. BWXT ITG (formerly Nordion) supplies ${ }^{103} \mathrm{Pd}$ in the form of $\left.{ }^{103} \mathrm{Pd}\right] \mathrm{PdCl}_{2}$, but primarily in high activities of several $\mathrm{GBq}$ destined for the production of brachytherapy seeds, in relatively low specific activity of $>60 \mathrm{Ci} / g$, and in a different chemical form (ammonium hydroxide solution) (www.bwxt.com). We are currently working on securing a continued supply of ${ }^{103} \mathrm{Pd}$ to further the investigations reported here.

With this report, we hope to contribute to the increasing interest in and availability of ${ }^{103} \mathrm{Pd}$ for research in non-brachytherapy applications. With the ${ }^{103} \mathrm{Pd}$ supply we had available, we were able to demonstrate that the preparation of a reliable ${ }^{103 \mathrm{~m}} \mathrm{Rh}$ generator is possible and that this can be done from $\left[{ }^{103} \mathrm{Pd}\right] \mathrm{Pd}$ of poor specific activity in any reasonably equipped radiochemistry laboratory. This makes research in ${ }^{103 m} \mathrm{Rh}$ as an Auger emitter feasible, provided that a supply of ${ }^{103} \mathrm{Pd}$ can be obtained. The generator was not tested at high ${ }^{103} \mathrm{Pd}$ radioactivities where radiolysis may degrade the chelator and cause higher breakthrough levels. At elution yields of $6 \%$, it would be relevant to apply several GBq to the generator, for elution yields on the order of $100-200 \mathrm{MBq}{ }^{103 \mathrm{~m}} \mathrm{Rh}$, which would be sufficient for investigating the radiotherapeutic efficacy of this radionuclide. For in vitro and preclinical studies on ${ }^{103 \mathrm{~m}} \mathrm{Rh}$ as an Auger radiotherapeutic, the reported generator system may be sufficient. Indeed, such studies would elucidate the necessary ${ }^{103 \mathrm{~m}} \mathrm{Rh}$ activities needed for such studies, since the cytotoxicity of ${ }^{103 \mathrm{~m}} \mathrm{Rh}$ remains to be investigated. Reported in vitro studies on Auger radiotherapy generally employ just a few MBqs, which would be possible to obtain using the reported generator. For in vivo use, it is our opinion that the short decay half-life of ${ }^{103 \mathrm{~m}} \mathrm{Rh}$ only allows for local administration, such as intratumoral or intracavitary. In such scenarios, less activity is administered, since systemic loss is less of a concern, and it would be reasonable to suggest a preclinical dose of around 5-10 MBq. Including an estimated preparation time of 1 hour, this would require a yield of minimum $20 \mathrm{MBq}{ }^{103 \mathrm{~m}} \mathrm{Rh}$ per elution. With a 5-6\% yield, this would in turn require loading the generator with about $400 \mathrm{MBq}$ of chelated ${ }^{103} \mathrm{Pd}$. Using the neutron irradiation technique that we have used here, this is an attainable activity, meaning that in our view, preclinical studies would be feasible. Clinical studies however, even with local administration, would likely require several GBq of administered activity, meaning that the reported generator would be too inefficient, especially given the radiolysis that can be expected from the up to $40 \mathrm{GBq}$ of contained ${ }^{103} \mathrm{Pd}$ that would be needed. Accordingly, while this generator may 
hopefully further the investigation of ${ }^{103 \mathrm{~m}} \mathrm{Rh}$ in Auger radiotherapy, additional research is needed before clinical translation.

\section{CONCLUSION}

We report the development of a cartridge-based, solid phase generator of high specific activity ${ }^{103 m} \mathrm{Rh}$ from ${ }^{103} \mathrm{Pd}$ obtained in poor specific activity from neutron-activated $\left[{ }^{102} \mathrm{Pd}\right] \mathrm{Pd}$ foils. The generator was based on ${ }^{103} \mathrm{Pd}$ chelated by a 16 aneS4 macrocyclic chelator, demonstrating that ${ }^{103} \mathrm{Rh}$ can leave this structure postdecay in a freely elutable form. Elution yields were around $6 \%$ with low ${ }^{103} \mathrm{Pd}$ breakthrough at less than $1 \%$ of the total eluted activity. Further studies will focus on improving elution yields and investigating the radiolabeling chemistry of the eluted ${ }^{103 \mathrm{~m}} \mathrm{Rh}$.

\section{ACKNOWLEDGEMENTS}

This work was supported by the Independent Research Fund Denmark [grant number 6111-00392B].

\section{REFERENCES}

Bartoś, B., Kowalska, E., Bilewicz, A., Skarnemark, G., 2009. 103Ru/103mRh generator. Journal of Radioanalytical and Nuclear Chemistry 279 (2), 655-657. doi: 10.1007/s10967-008-7346-9.

Bernhardt, P., Forssell-aronsson, E., Jacobsson, L., Skarnemark, G., 2001. Low-energy Electron Emitters for Targeted Radiotherapy of Small Tumours. Acta Oncologica 40 (5), 602-608. doi: $10.1080 / 028418601750444141$.

www.bwxt.com. Palladium-103 Radiochemical Palladium Chloride Solution. [accessed November 11th 2019] https://www.bwxt.com/media/7d8090ca-bbeb-479a-a45e3ae1aa5fa95d/kEXMAg/Documents/Literature/Medical\%20lsotopes/Palladium-103\%20Radiochemical.pdf 
430 Cooper, S.R., Jones W.B., Rawle, S.C., 1996. Ten-membered rings or larger with one or more sulfur atoms. In 431 Comprehensive Heterocyclic Chemistry II: A Review of the Literature 1982-1995, 9:843-62. Elsevir.

432 https://doi.org/10.1016/B978-008096518-5.00238-0

433

434

435

436

437

438

439

440

441

442

443

444

445

446

447

448

449

450

451

452

453

454

455

456

457

458

459

460

461

462

Edem, P.E., Fonslet, J., Kjær, A., Herth, M., Severin, G., 2016. In Vivo Radionuclide Generators for Diagnostics and Therapy. Bioinorganic Chemistry and Applications, Article ID 6148357, 8 pages. doi: 10.1155/2016/6148357.

Fassbender, M., Nortier, F.M., Schroeder, I.W., van der Walt, T.N., 1999. The Production of 103Pd via the natAg(p,x)103Pd Nuclear Process. Radiochimica Acta 87 (3-4), 87-91. doi: 10.1524/ract.1999.87.34.87.

Ferro, A., Bae, H. J., Yenokyan, G., Le, Y., Mcnutt, T., Mian, O., Gergis, C., Haviland, C., Deweese, T. L., Song, D. Y., 2018. Reductions in prostatic doses are associated with less acute morbidity in patients undergoing Pd-103 brachytherapy : Substantiation of the rationale for focal therapy. Brachytherapy 17, 313-318. doi: 10.1016/j.brachy.2017.10.008.

Grudzinski, J., Marsh, I., Titz, B., Jeffery, J., Longino, M., Kozak, K., Lange, K., Larrabee, J., Weichmann, A., Moser, A., Bednarz, B., 2018. CLR 125 Auger Electrons for the Targeted Radiotherapy of Triple-Negative Breast Cancer. Cancer Biotherapy and Radiopharmaceuticals 33 (3), 87-95. doi: 10.1089/cbr.2017.2376.

IAEA, International Atomic Energy Agency, 2009. Cyclotron Produced Radionuclides: Physical Characteristics and Production Methods. Technical report series 468, 209-214.

Kozempel, J., Mokhodoeva, O., Vlk, M., 2018. Progress in Targeted Alpha-Particle Therapy. What We Learned about Recoils Release from In Vivo Generators. Molecules 23, 581. doi:10.3390/molecules23030581.

Li, N., Struttman, M., Higginbotham, C., Grall, A. J., Skerlj, J.F., Vollano, J.F., Bridger, S.A., Ochrymowycz, L.A., Ketring, A.R., Abrams, M.J., Volkert, W.A., 1997. Biodistribution of model ${ }^{105}$ Rh-labeled tetradentate thiamacrocycles in rats. Nuclear Medicine \& Biology 24 (1), 85-92. doi.org/10.1016/S0969-8051(96)001771.

Lyczko, M., Pruszynski, M., Majkowska-Pilip, A., Lyczko, K., Was, B., Meczynska-Wielgosz, S., Kruszewski, M., 
463

464 465

466

467

468

469

470

471

472

473

474

475

476

477

478

479

480

481

482

483

484

485

486

487

488

489

490

491

492

493

494

495

Szkliniarz, K. Jastrzebski, J., 2017. ${ }^{211}$ At labeled substance P ( 5 - 11 ) as potential radiopharmaceutical for glioma treatment. Nuclear Medicine and Biology 53, 1-8. doi: 10.1016/j.nucmedbio.2017.05.008.

Mastren, T., Radchenko, V., Hopkins, P. D., Engle, J. W., Weidner, J. W., Copping, R., Brugh, M., Nortier, F. M., Birnbaum, E. R., John, K. D., Fassbender, M. E., 2017. Separation of ${ }^{103}$ Ru from a proton irradiated thorium matrix : A potential source of Auger therapy radionuclide ${ }^{103 \mathrm{~m}} \mathrm{Rh}$, PLoS ONE 12 (12), e0190308. doi: 10.1371/journal.pone.0190308.

De Frenne, D., 2009. Nuclear Data Sheets for $A=103$, Nuclear Data Sheets 110, 2081-2256. doi:10.1016/j.nds.2009.08.002

NuDat2 (2004). Release 2.7. National Nuclear Data Center (NNDC), Brookhaven National Laboratory, NY (USA). [accessed November 11th 2019] http://www.nndc.bnl.gov/nudat2/chartNuc.jsp

Reissig, F., Mamat, C., Steinbach, J., Pietzsch, H., 2016. Direct and Auger Electron-Induced, Single- and Double-Strand Breaks on Plasmid DNA Caused by ${ }^{99 \mathrm{~m}}$ Tc-Labeled Pyrene Derivatives and the Effect of Bonding Distance. PLoS ONE 11 (9), e0161973. doi: 10.1371/journal.pone.0161973.

Rooyen, J. Van, Szucs, Z., Rijn, J., 2008. A possible in vivo generator ${ }^{103} \mathrm{Pd} /{ }^{103 \mathrm{~m}} \mathrm{Rh}$ - Recoil considerations. Applied Radiation and Isotopes 66, 1346-1349. doi: 10.1016/j.apradiso.2008.02.088.

Severin, G.W., Kristensen, L.K., Nielsen, C.H., Fonslet, J., Jensen, A.I., Frellsen, A.F., Jensen, K.M., Elema, D.R., Maecke, H., Kjaer, A., Johnston, K., Koster, U., 2017. Neodymium-140 DOTA-LM3: Evaluation of an In Vivo Generator for PET with a Non-Internalizing Vector. Frontiers in Medicine 4, 1-9. doi: 10.3389/fmed.2017.00098.

Skarnemark, G., Ödegaard-Jensen, A., Nilsson, J., Bartos, B., Kowalska, E., Bilewicz, A., Bernhardt, P., 2009. Production of 103mRh for cancer therapy, Journal of Radioanalytical and Nuclear Chemistry 280 (2), 371373. doi: 10.1007/s10967-009-0529-1.

Steeg, P.S., 2016. Targeting metastasis. Nature Reviews Cancer 16 (4), 201-218. doi: 10.1038/nrc.2016.25.

Sudar, S., Cserpak, F., Qaim, S.M., 2002. Measurements and nuclear model calculations on proton-induced 
496

497

498

499

500

501

502

503

504

505

506

507

508

509

510

511

512

513

514

515

516

517

518

519

520

521

522

523

524

525

526

527

528

reactions on ${ }^{103} \mathrm{Rh}$ up to $40 \mathrm{MeV}$ : evaluation of the excitation function of the ${ }^{103} \mathrm{Rh}(\mathrm{p}, \mathrm{n}){ }^{103} \mathrm{Pd}$ reaction relevant to the production of the therapeutic radionuclide ${ }^{103} \mathrm{Pd}$, Applied Radiation and Isotopes 56, 821831.

Tavares, A.A.S. \& Tavares, J.M.R.S., 2010. ${ }^{99 \mathrm{~m}} \mathrm{Tc}$ Auger electrons for targeted tumour therapy: a review. International journal of radiation biology 86 (4), 261-70. doi: 10.3109/09553000903564083.

Thisgaard, H., Halle, B., Aaberg-jessen, C., Olsen, B.B., Sofie, A., Therkelsen, N., Dam, J.H., Langkjær, N., Munthe, S., Någren, K., Høilund-carlsen, F., Kristensen, B.W., 2016. Highly Effective Auger-Electron Therapy in an Orthotopic Glioblastoma Xenograft Model using Convection-Enhanced Delivery. Theranostics 6 (12), 2278-2291. doi: 10.7150/thno.15898.

Venkatesh, M., Goswami, N., Volkert, W.A., Schlemper, E.O., Ketring, A.R., Barnes, C.L., Jurisson, S., 1996. An Rh-105 Complex of Tetrathiacyclohexadecane Diol with Potential for Formulating Bifunctional Chelates. Nuclear Medicine and Biology 23 (1), 33-40. doi:10.1016/0969-8051(95)02012-8.

Zeevaart, J.R., Szucs, Z., Takacs, S., Van Rooyen, J., Jansen, D., 2012. Recoil and conversion electron implications to be taken into account in the design of therapeutic radiopharmaceuticals utilising in vivo generators. Journal of Labelled Compounds \& Radiopharmaceuticals 55, 115-119. doi: 10.1002/jlcr.2906.

\section{FIGURE CAPTIONS}

Figure 1. Simplified decay scheme from ${ }^{103} \mathrm{Pd}$ and ${ }^{103} \mathrm{Ru}$ to ${ }^{103} \mathrm{Rh}$ through ${ }^{103 \mathrm{~m}} \mathrm{Rh}$.

Scheme 1. Organic and radiochemical synthesis

Figure 2. Example graph of LSC counting of eluate from the ${ }^{103 \mathrm{~m}} \mathrm{Rh}$ generator. Plotted as cps on a logarithmic scale against time. Each point represents an LSC measurement done over 10 minutes. After about 10 hours, the counts are seen to stabilize at a plateau attributed to ${ }^{103} \mathrm{Pd}$ breakthrough. The decay half-life of the counts with the ${ }^{103} \mathrm{Pd}$ plateau deducted was in this particular case found to be 58 minutes. 
Figure 3. Recorded X-ray spectrum of produced ${ }^{103 \mathrm{~m}} \mathrm{Rh}$. Two main compound peaks were observed at 20.2 and $22.7 \mathrm{keV}$. This corresponded with literature values: $20.1 \mathrm{keV}(2.2 \%), 20.2 \mathrm{keV}(4.1 \%), 22.7$ (1.0\%), 23.1 (0.16\%), obtained from NuDat 2.7 .

\section{TABLES}

Table 1. Properties of generator elutions using dilute $\mathrm{HCl}(1.0 \mathrm{M}$ or $0.1 \mathrm{M})$ or dilute $\mathrm{HCl}(1.0 \mathrm{M})$ mixed with 540 acetonitrile (95:5). ${ }^{103 \mathrm{~m}} \mathrm{Rh}$ half-life denotes the observed half-life of activity ascribed to ${ }^{103 \mathrm{~m}} \mathrm{Rh}$ in the initial 10 $\mathrm{h}$ of LSC counting (litt. value: $56.114 \pm 20 \mathrm{~min}$, De Frenne 2009). ${ }^{103 \mathrm{~m}} \mathrm{Rh}$ yield is the percentage of eluted ${ }^{103 \mathrm{~m}} \mathrm{Rh}$ activity of the entire ${ }^{103} \mathrm{Pd}$ activity retained on the generator (theoretical max). ${ }^{103} \mathrm{Pd}$ breakthrough is the percentage of eluted ${ }^{103} \mathrm{Pd}$ activity of the entire ${ }^{103} \mathrm{Pd}$ activity retained on the generator. ${ }^{103} \mathrm{Pd}(\%)$ is the amount of ${ }^{103} \mathrm{Pd}$ activity of the total eluted activity. The radiochemical purity (RCP) of ${ }^{103 \mathrm{~m}} \mathrm{Rh}$ is estimated as the eluted activity ascribed to ${ }^{103 \mathrm{~m}} \mathrm{Rh}$ as a percentage of the entire eluted activity. The apparent molar activity is the eluted activity of ${ }^{103 \mathrm{~m}} \mathrm{Rh}$ decay-corrected to when the $\left[{ }^{103} \mathrm{Pd}\right] \mathrm{Pd}$ was initially dissolved divided by the eluted Pd. All data were done in triplicate $(n=3)$ on different dilutions of the same elution, error is shown as standard deviation.

\begin{tabular}{|c|c|c|c|}
\hline Elution medium & Aq. $\mathrm{HCl}(1.0 \mathrm{M}, 1.0 \mathrm{~mL})$ & Aq. $\mathrm{HCl}(0.1 \mathrm{M}, 1.0 \mathrm{~mL})$ & $0.1 \mathrm{M} \mathrm{HCl}: \mathrm{ACN}(95: 5)$ \\
\hline${ }^{103 m} \mathrm{Rh}$ half-life measured & $56.9 \pm 1.1 \mathrm{~min}$ & $57.6 \pm 3.0 \mathrm{~min}$ & $59.3 \pm 3.0 \mathrm{~min}$ \\
\hline${ }^{103 m} \mathrm{Rh}$ yield & $5.81 \pm 0.14 \%$ & $5.84 \pm 0.03 \%$ & $7.60 \pm 0.12 \%$ \\
\hline${ }^{103} \mathrm{Pd}$ breakthrough & $0.0221 \pm 0.0055 \%$ & $0.0424 \pm 0.0005 \%$ & $0.0692 \pm 0.0039 \%$ \\
\hline${ }^{103} \mathrm{Pd}(\%)$ of eluted activity & $0.38 \pm 0.09 \%$ & $0.72 \pm 0.007 \%$ & $0.90 \pm 0.05 \%$ \\
\hline RCP of eluted ${ }^{103 m} \mathrm{Rh}$ (est.) & $99.62 \pm 0.09 \%$ & $99.28 \pm 0.01 \%$ & $99.10 \pm 0.05 \%$ \\
\hline $\begin{array}{l}\text { Apparent mol. act. of }{ }^{103 \mathrm{~m}} \mathrm{Rh} \\
\text { (dc) }\end{array}$ & $26.6 \pm 5.5 \mathrm{MBq} / \mathrm{nmol}$ & $13.8 \pm 0.2 \mathrm{MBq} / \mathrm{nmol}$ & $10.5 \pm 0.9 \mathrm{MBq} / \mathrm{nmol}$ \\
\hline
\end{tabular}




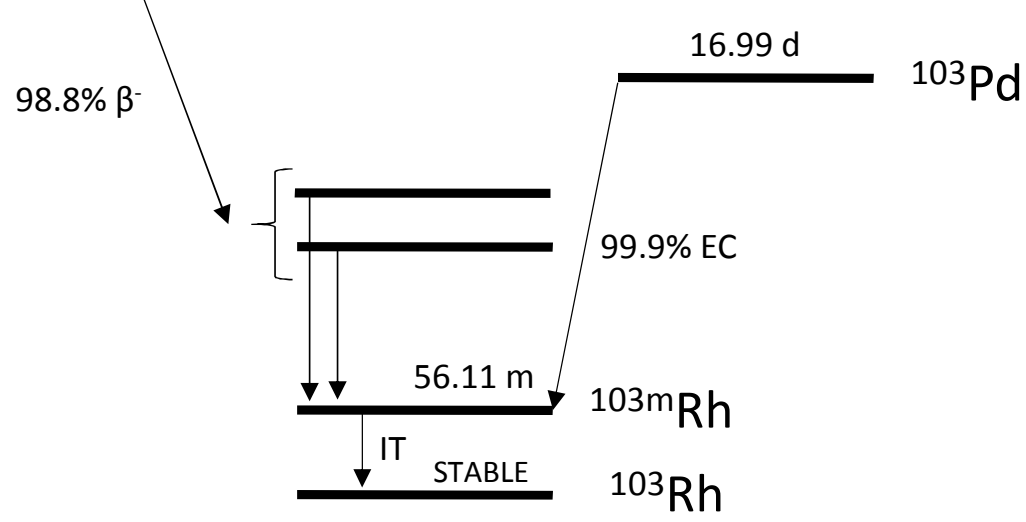




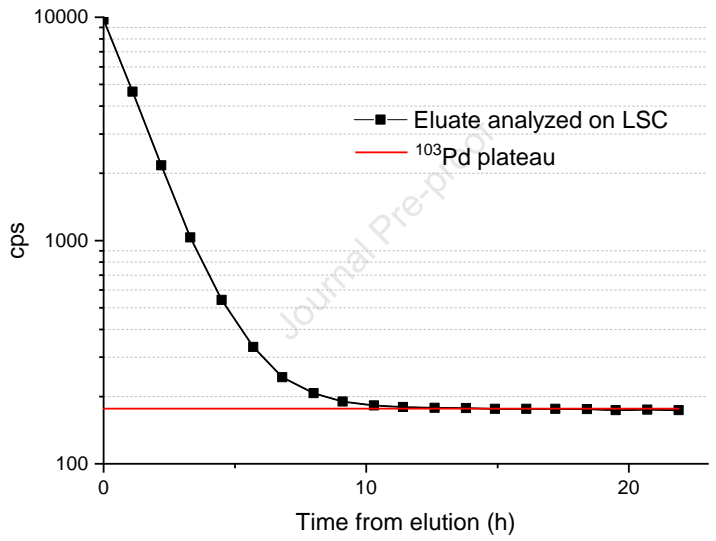




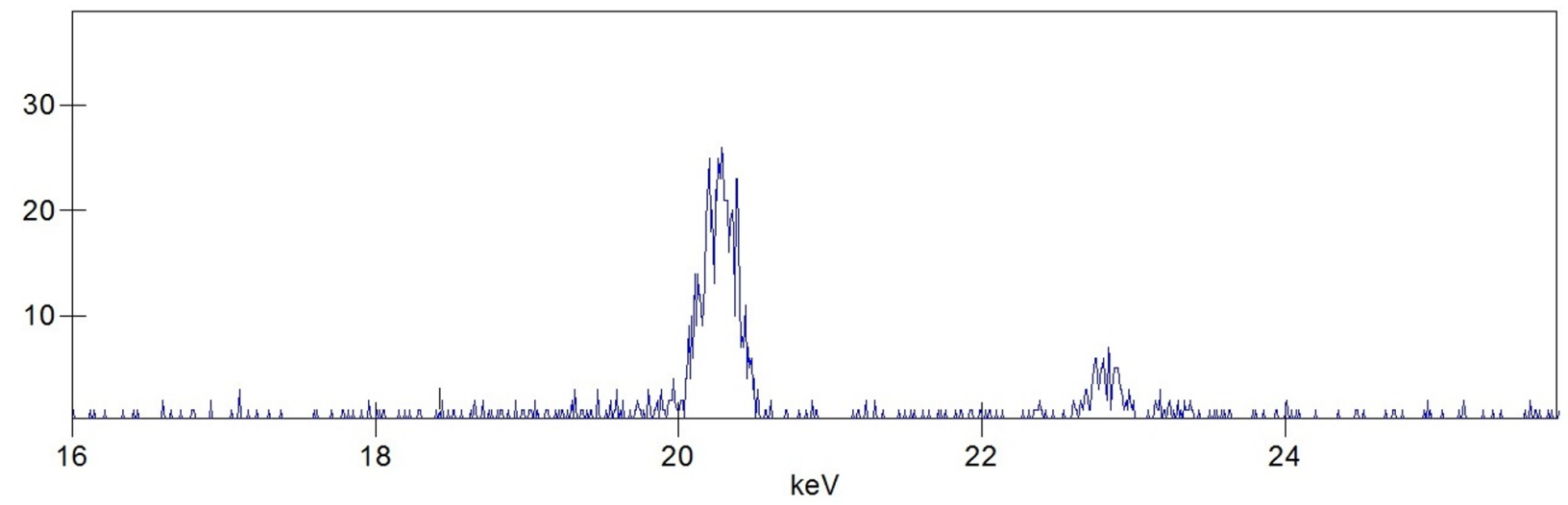




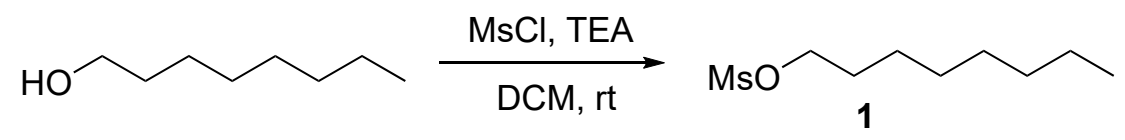

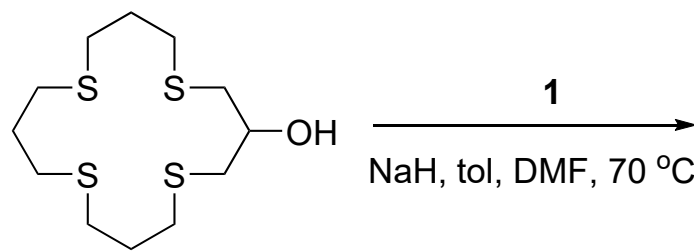

2

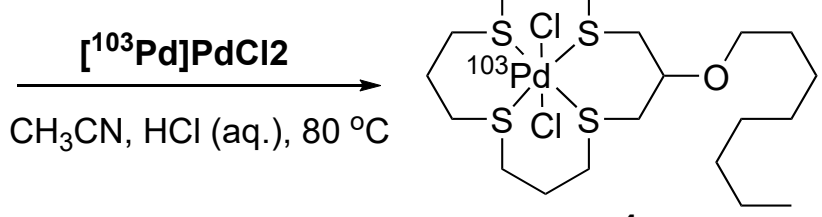

4

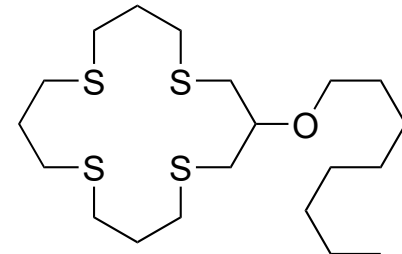

3

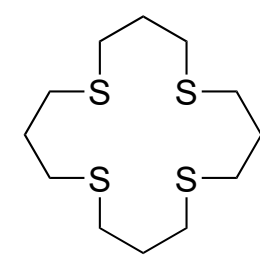

5 (16aneS4) 


\section{Highlights:}

- $\quad\left[{ }^{103} \mathrm{Pd}\right] \mathrm{PdCl}_{2}$ was obtained by dissolving neutron irradiated ${ }^{102} \mathrm{Pd}$-enriched targets

- $\quad\left[{ }^{103} \mathrm{Pd}\right] \mathrm{Pd}$ was chelated by a 16 aneS4-octyl derivative and trapped on a C18 support

- Elution of this generator provided ${ }^{103 m} \mathrm{Rh}$ in excellent radiochemical purity

- The demonstrated generator will allow investigating ${ }^{103 \mathrm{~m}} \mathrm{Rh}$ for Auger radiotherapy 


\section{Declaration of interests}

$\bigotimes$ The authors declare that they have no known competing financial interests or personal relationships that could have appeared to influence the work reported in this paper.

$\square$ The authors declare the following financial interests/personal relationships which may be considered as potential competing interests: 